\title{
Práticas de Agressividade Competitiva em Empresas do Setor de Software do Rio Grande do Sul: um estudo EXPLORATÓRIO COM EXECUTIVOS
}

\author{
Competitive Aggressiveness Practices in Software Sector \\ Companies of Rio Grande do Sul: an exploratory study with \\ executives
}

\begin{abstract}
Cristina Dai Prá Martens
Professora do Programa de Mestrado e Doutorado em Administração e do Programa de Mestrado Profissional em Administração Universidade Nove de Julho - UNINOVE - São Paulo - SP - Brasil. E-mail: cristinadm@uninove.br
\end{abstract}

Henrique Mello Rodrigues de Freitas

Professor Associado IV da Escola de Administração e professor do Programa de Pós-Graduação em Administração - da Universidade Federal do RIo Grande do SUl - Porto Alegre - RS - Brasil. E-mail: hf@ea.ufrgs.br

\section{Anatália Saraiva Martins Ramos}

Professora Associado IV do Departamento de Ciências Administrativas da Universidade Federal do Rio Grande do Norte, professora no Programa de Pós-Graduação em Administração e do Departamento de Administração na Universidade Federal do Rio Grande do Norte - Natal - RN - Brasil.E-mail: anatalia@ufrnet.br

\section{Jean-Pierre Boissin}

Professor do Institut d'Administration des Entreprises - IAE da Université Pierre Mendès France - Grenoble - França.

E-mail: jean-pierre.boissin@upmf-grenoble.fr

\section{Resumo}

Este artigo trata sobre a agressividade competitiva, definida como a propensão de uma organização em desafiar seus concorrentes para entrar no mercado ou melhorar sua posição. Tem como objetivo investigar as práticas de agressividade competitiva adotadas pelas empresas no contexto de setores industriais dinâmicos, a fim de cotejar seus construtos com a experiência relatada por executivos. Em particular, este estudo foca empresas do setor de software consideradas referências em empreendedorismo no estado do Rio Grande do Sul. A pesquisa foi de caráter exploratório e qualitativo, com coleta de dados por meio de entrevistas em profundidade com dirigentes de 13 empresas de software e serviços. Os resultados retratam como a agressividade competitiva repercute nas empresas no que se refere à reação à concorrência, competição financeira, competição em negócios e marketing, apresentando práticas gerenciais que a evidenciam. O estudo conclui com a consolidação de um conjunto de práticas sobre a agressividade competitiva nas empresas pesquisadas.

Palavras-chave: Agressividade Competitiva. Orientação Empreendedora. Empreendedorismo. Estratégia Organizacional. Empresas de Software.

\section{Abstract}

This article discusses about the competitive aggressiveness, defined as the propensity of an organization to challenge its competitors to enter the market or to improve their position. Its aims to investigate competitive aggressiveness practices adopted in the context of dynamic industrial sectors, in order to compare its constructs with the experience reported by executives. In particular, this study focuses on software companies considered reference in entrepreneurship, in the sector, in the state of Rio Grande do Sul. The research was exploratory and qualitative, with data collection through in-depth interviews with executives of thirteen software and services companies. The results show how competitive aggressiveness reflects in companies concerting Reaction to competitiveness, Financial competition, Competition in business and Marketing. Competitive aggressiveness practices are presented. Finally, the study consolidates of a set competitive aggressiveness practices in the surveyed companies.

Key words: Competitive Aggressiveness. Entrepreneurial Orientation. Entrepreneurship. Organizational Strategy. Software Companies. 


\section{INTRODUÇÃO}

A agressividade competitiva denota uma forte e ousada atuação competitiva de uma organização frente à concorrência. Ela retrata organizações que respondem a tendências já existentes no mercado $e$ se movem de forma agressiva em função das ações dos concorrentes. É uma característica organizacional importante, posto que contribui para a superação de rivais, para a busca de manutenção ou ganho de mercado e para o combate a ameaças. (LUMPKIN; DESS, 2001)

Num contexto mais amplo, a agressividade competitiva é considerada uma das dimensões da Orientação Empreendedora, definida por Lumpkin e Dess (1996) como um processo associado a métodos, estilos e escolhas estratégicas e é um tema que emerge da literatura de estratégia no final da década de 1970 e início dos anos 1980 (MILLER; FRIESEN, 1982; MILLER, 1983). Organizações empreendedoras são detentoras de uma postura empreendedora (COVIN; SLEVIN, 1991; MILLER, 1983), caracterizada pela presença de inovatividade, assunção de riscos, proatividade, autonomia e agressividade competitiva. Assim, a agressividade competitiva é considerada uma importante característica no contexto de empreendedorismo.

Trabalhos sobre a agressividade competitiva são relativamente recentes na literatura de estratégia organizacional, com uma abrangência de pouco mais de duas décadas. Um dos primeiros estudos neste campo é o de Covin e Covin (1990), eles investigaram a sua relação com o desempenho de pequenas empresas. Eles apontam que a agressividade competitiva permite às organizações lidar mais adequadamente com a presença e as pressões dos concorrentes. Em sentido semelhante, Lumpkin e Dess (2001) argumentam que uma forte agressividade competitiva propicia à empresa a capacidade de ser um ator decisivo no campo competitivo e agir com força para proteger ou melhorar a sua posição no mercado. Stambaugh et al. (2009) reforçam que a agressividade competitiva trata de práticas organizacionais e processos que estão associadas à propensão de uma empresa a tomar ações competitivas, e afirmam que este é um tema com espaço para o desenvolvimento de estudos.

Na literatura nacional, pode-se destacar o caráter inédito do tema agressividade competitiva, abordado apenas de forma agregada com as dimensões da orientação empreendedora, a exemplo dos estudos de Silva, Gomes e Correia (2009), Martens, Freitas e Andres (2011) e Freitas et al. (2012). A agressividade competitiva, assim como a postura empreendedora de uma organização, é um fenômeno comportamental e pode ser gerenciada. Nesse sentido, estudos que possibilitem uma melhor compreensão sobre a agressividade competitiva no contexto organizacional podem contribuir para o desenvolvimento desse comportamento em organizações, além do fato de que a prática das empresas pode ser enriquecedora da própria teoria.

Assim, tendo em vista a relevância do tema e a lacuna de estudos nacionais a respeito, este trabalho tem como objetivo investigar as práticas de agressividade competitiva adotadas pelas empresas no contexto de setores industriais dinâmicos, a fim de cotejar seus construtos com a experiência relatada por executivos. Em particular, este estudo foca empresas do setor de software consideradas referência em empreendedorismo no setor, localizadas no estado do Rio Grande do Sul.

Em termos de política industrial, o setor de tecnologia de informação e comunicações tem sido considerado estratégico para o desenvolvimento nacional (BRASIL, 2011) e recebe visibilidade política após o anúncio do programa "TI Maior" (2012), o qual pretende transformar o cenário nacional do setor de software. Segundo a Associação Brasileira das Empresas de Software, o mercado mundial de software e serviços atingiu em 2010 o valor de U\$ 884,5 bilhões, e o Brasil subiu uma posição no ranking mundial, passando ao $11^{\circ}$ lugar com um mercado interno de U\$ 17,3 bilhões (ABES, 2011). Dessa maneira, o setor de software foi escolhido como campo de estudo tendo em vista seu destaque econômico, pelo seu dinamismo e rápido ritmo de crescimento que tem apresentado nos últimos anos.

Após esta introdução, na seção 2 é feita uma retomada da literatura sobre a agressividade competitiva, sob a ótica da orientação empreendedora, bem como é apresentada a base conceitual adotada para a realização do estudo. A seção 3 apresenta o método de pesquisa utilizado. Na seção 4 é feita a análise dos resultados, dando ênfase para práticas de ações efetivas de agressividade competitiva nas empresas foco 
do estudo. A seção 5 discute os resultados e a seção 6 apresenta considerações finais do estudo.

\section{Agressividade Competitiva no Contexto de Orientação EMPREENDEDORA}

A agressividade competitiva, também denominada como agressividade concorrencial, é conceituada como a propensão de uma organização a direta $e$ intensamente desafiar os seus concorrentes para entrar no mercado ou melhorar seu posicionamento (LUMPKIN; DESS, 1996). A agressividade competitiva é uma importante dimensão do empreendedorismo no nível organizacional, já que contribui para a superação de rivais. Chen e Hambrick (1995) corroboram esse conceito, tratando a agressividade competitiva como a tendência a responder agressivamente às ações da concorrência. Eles também a denominam responsividade, ou seja, a resposta da organização a partir das ações da concorrência visando vantagem competitiva.

Para Lumpkin e Dess (1996), quando observada no contexto de empreendedorismo, a agressividade competitiva parece fortemente relacionada com as demais dimensões da orientação empreendedora, que são: inovatividade, assunção de riscos, proatividade e autonomia. No contexto de comparação entre Brasil e Portugal, os autores Silva, Gomes e Correia (2009) apontam que os empreendedores brasileiros apresentaram um comportamento de competitividade agressiva mais elevado do que o dos portugueses. Os autores atribuem tal fato a uma baixa disponibilidade de recursos financeiros no Brasil a qual pode acarretar maior concorrência e, consequentemente, exigir desses empreendedores um comportamento competitivo mais agressivo. Por outro lado, mais recentemente, Vora, Vora e Polley (2012) estudaram a aplicabilidade dos construtos de orientação empreendedora (OE) no contexto de médias empresas americanas e constataram que essas empresas tinham altos níveis de autonomia $e$ proatividade, exibiam níveis moderados de inovação e assunção de riscos, mas apenas um baixo nível de agressividade competitiva. Tais resultados mostram que uma organização empreendedora pode ser caracterizada por todas ou por apenas algumas das dimensões elencadas por Lumpkin e Dess (1996), dependendo do contexto e da oportunidade empreendedora que persegue.
Outro conceito encontrado na literatura é o de Venkatraman (1989), que defende que a agressividade competitiva reflete a postura adotada na alocação de recursos para ganhar posições em determinado mercado de forma mais rápida que os competidores. Segundo o autor, essa agressividade pode ser baseada em inovação de produto, desenvolvimento de mercado, alto investimento para melhorar participação no mercado e posição competitiva. Essa visão da agressividade competitiva tem um forte elo com o conceito de inovatividade.

Em estudo recente, Stambaugh, Yu e Dubinsky (2011) tratam da agressividade competitiva e da inovatividade como fatores que orientam ações competitivas. Eles argumentam que ambas as dimensões da orientação empreendedora contribuem para o desenvolvimento de ações competitivas, porém com lógicas subjacentes distintas: enquanto a inovatividade foca na introdução de novos produtos, a agressividade competitiva é focada nos rivais. Também afirmam que uma organização pode ter um alto nível de ambas as dimensões.

Os estudos de Covin e Slevin (1989) e Covin e Covin (1990) tratam a agressividade competitiva como parte da proatividade de uma organização, não fazendo diferença entre os dois conceitos. Entretanto, Lumpkin e Dess (1996) apontam uma importante distinção entre elas: a proatividade refere-se a como a organização transforma oportunidades em novos negócios, ao passo que a agressividade competitiva tem foco nos competidores, tratando de como as organizações respondem às tendências e demandas que já existem no mercado. Em outras palavras, a proatividade é uma resposta a oportunidades e a agressividade competitiva uma resposta a ameaças. (LUMPKIN; DESS, 2001)

Em sentido semelhante, Sandberg (2002) trata do comportamento reativo da empresa. Segundo a autora, esse comportamento pode ser visto como um contínuo, que vai da proatividade à reatividade, dicotomia frequentemente refletida na literatura de comportamento estratégico. Para essa abordagem, num extremo está a proatividade e noutro, a agressividade competitiva. Contudo, num estudo sobre essas duas dimensões da orientação empreendedora, Lumpkin e Dess (2001) afirmam que elas podem ocorrer de forma sequencial e dinâmica em uma organização, e que podem variar independentemente. Os autores lembram que a proatividade e a agressividade competitiva 
constituem avenidas diferentes para o desenvolvimento do empreendedorismo em organizações. (LUMPKIN; DESS, 1997)

Algumas evidências de agressividade competitiva em organizações podem ser alcançadas ao avaliar, por exemplo, a postura gerencial em termos de competitividade (COVIN; COVIN, 1990). Para Lumpkin e Dess (1996) e Chen (1996), ela também pode ser refletida na vontade de utilizar métodos de competição não convencionais no lugar de métodos tradicionais. Para novos entrantes, os autores sugerem, como exemplos de ações, a adoção de táticas não convencionais para desafiar os líderes da indústria; analisar e focar as falhas dos competidores; focar no alto valor adicionado a produtos, enquanto gastos são cuidadosamente monitorados. No caso de organizações já existentes, algumas abordagens de agressividade competitiva podem ser: fazer as coisas de forma diferente; mudar o contexto, redefinindo produtos/serviços e seus canais de mercado ou escopo. (LUMPKIN; DESS, 1996)

Nessa direção, Macmillan e Day (1987) estudaram o efeito da entrada agressiva de empresas que se aventuram em novos mercados industriais e mostraram que estratégias agressivas refletem em maior desempenho organizacional, particularmente quanto à obtenção de maior retorno no investimento (ROI) e crescimento do market share. As práticas de agressividade competitiva mais comuns relatadas pelos autores foram: estabelecimento de metas ambiciosas de market share, investimento maciço na capacidade da nova planta industrial, desenvolvimento de força de vendas, promoção de vendas, publicidade, qualidade, serviço e/ou programas de preços altamente agressivos em relação aos concorrentes.

Para Venkatraman (1989), a agressividade competitiva também pode ser identificada na noção de explosão, que retrata o aumento da posição competitiva em pouco tempo, a estratégia de multiplicação e a perseguição de parte do mercado como um importante caminho para atingir a rentabilidade. Ainda, outros exemplos podem ser ilustrados, como a entrada num mercado já identificado por outros competidores, e a redução de preços em resposta a uma mudança competitiva. (LUMPKIN; DESS, 1996)

Adicionalmente, Stambaugh et al. (2009) tratam da conceituação de Chen (1996) de consciência, motivação e capacidade como direcionadores do com- portamento competitivo de uma empresa. Os autores ampliam esses conceitos propondo três construtos: consciência rival, que trata do nível de informações sobre as ações, intenções e capacidades de seus rivais; motivação para superar, que sugere uma propensão ou entusiasmo para enfrentar déficits de desempenho por meio de ações competitivas; capacidade de ação, que se refere ao nível de recursos disponíveis para iniciar e responder às ações da concorrência.

A partir da revisão da literatura, o Quadro 1 apresenta elementos que caracterizam a agressividade competitiva nas organizações, identificados em diferentes estudos.

\begin{tabular}{|c|c|}
\hline ELEMENTOS DA AGRESSIVIDADE COMPETITIVA & Autores \\
\hline $\begin{array}{l}\text { Gastos agressivos (se comparados com os } \\
\text { concorrentes) em marketing, qualidade } \\
\text { de produtos e serviços, ou capacidade de } \\
\text { manufatura. }\end{array}$ & $\begin{array}{l}\text { Macmillan e } \\
\text { Day (1987) }\end{array}$ \\
\hline $\begin{array}{l}\text { Sacrifica a lucratividade para ganhar parcela } \\
\text { de mercado. } \\
\text { Corta preços para aumentar participação no } \\
\text { mercado. } \\
\text { Coloca preços abaixo da competição. } \\
\text { Busca posição no mercado à custa de fluxo } \\
\text { de caixa ou rentabilidade. }\end{array}$ & $\begin{array}{l}\text { Venkatraman } \\
\text { (1989) }\end{array}$ \\
\hline $\begin{array}{l}\text { Normalmente responde às ações que a } \\
\text { concorrência inicia. } \\
\text { Tipicamente adota postura competitiva e } \\
\text { desqualifica os concorrentes. }\end{array}$ & $\begin{array}{l}\text { Covin e Covin } \\
(1991)\end{array}$ \\
\hline $\begin{array}{l}\text { Mover-se em função das ações dos } \\
\text { concorrentes. } \\
\text { Responder agressivamente às ações dos } \\
\text { concorrentes. }\end{array}$ & $\begin{array}{l}\text { Chen e } \\
\text { Hambrick } \\
\text { (1995) }\end{array}$ \\
\hline $\begin{array}{l}\text { Desenvolve ações competitivas com base na } \\
\text { atuação da concorrência }\end{array}$ & $\begin{array}{l}\text { Stambaugh, } \\
\text { Yu e Dubinsky } \\
\text { (2011) }\end{array}$ \\
\hline $\begin{array}{l}\text { Postura agressiva para combater tendências } \\
\text { da indústria que podem ameaçar a } \\
\text { sobrevivência ou posição competitiva. } \\
\text { Melhora posição competitiva por entrar } \\
\text { em mercados com preços muito baixos, } \\
\text { copiando práticas de negócios ou técnicas } \\
\text { de competidores de sucesso, ou marketing } \\
\text { oportuno de anúncio de novos produtos ou } \\
\text { tecnologias. } \\
\text { Uso de métodos de competição não } \\
\text { convencionais. } \\
\text { É agressiva e intensamente competitiva. } \\
\text { Adota postura competitiva no sentido de } \\
\text { desqualificar o competidor. }\end{array}$ & $\begin{array}{l}\text { Lumpkin e } \\
\text { Dess (1996; } \\
\text { 2001); Dess } \\
\text { e Lumpkin } \\
\text { (2005) }\end{array}$ \\
\hline
\end{tabular}

Quadro 1: Elementos que caracterizam a Agressividade Competitiva

Fonte: Elaborado pelos autores deste artigo 
Neste trabalho, a linha conceitual adotada para definir agressividade competitiva é a de Macmillan e Day (1987), Chen e Hambrick (1995) e de Lumpkin e Dess (1996), para quem a agressividade competitiva é a propensão da organização a responder agressivamente às ações da concorrência para entrar no mercado ou melhorar seu posicionamento.

A seção a seguir apresenta esses elementos consolidados da literatura organizados em uma base conceitual para estudo da agressividade competitiva em organizações.

\subsection{Base Conceitual sobre a Agressividade Competitiva}

Com base nos elementos sobre a agressividade competitiva identificados na literatura e apresentados no Quadro 1, partiu-se para a elaboração de uma base conceitual que possibilitasse observar e caracterizar a agressividade competitiva no contexto organizacional. Assim, o Quadro 2 apresenta categorias e elementos da agressividade competitiva, fundamentados em estudos clássicos sobre esse conceito e sobre orientação empreendedora.

\begin{tabular}{|c|c|}
\hline Categorias & Elementos da Agressividade Competitiva \\
\hline $\begin{array}{l}\text { Reação à } \\
\text { concorrência }\end{array}$ & $\begin{array}{l}\text { Mover-se em função das ações dos } \\
\text { concorrentes. } \\
\text { Responder agressivamente às ações dos } \\
\text { concorrentes. } \\
\text { Empresa muito agressiva e intensamente } \\
\text { competitiva. }\end{array}$ \\
\hline $\begin{array}{l}\text { Competição } \\
\text { em negócios }\end{array}$ & $\begin{array}{l}\text { Uso de métodos de competição não } \\
\text { convencionais. } \\
\text { Postura agressiva para combater tendências } \\
\text { da indústria que podem ameaçar a } \\
\text { sobrevivência ou posição competitiva. } \\
\text { Tipicamente adota uma postura muito } \\
\text { competitiva, desqualificando os competidores. } \\
\text { Copia práticas de negócios ou técnicas de } \\
\text { competidores de sucesso. }\end{array}$ \\
\hline Marketing & $\begin{array}{l}\text { Faz marketing oportuno de novos produtos } \\
\text { ou tecnologias. } \\
\text { Investimentos agressivos em marketing. }\end{array}$ \\
\hline $\begin{array}{l}\text { Competição } \\
\text { financeira }\end{array}$ & $\begin{array}{l}\text { Busca posição no mercado à custa de fluxo } \\
\text { de caixa ou rentabilidade. } \\
\text { Reduz preços para aumentar a participação } \\
\text { no mercado. } \\
\text { Coloca preços abaixo da competição. }\end{array}$ \\
\hline
\end{tabular}

Quadro 2: Base conceitual sobre agressividade competitiva, suas categorias e elementos

Fonte: Adaptado de Macmillan e Day (1987), Venkatraman (1989), Covin e Covin (1991), Chen e Hambrick (1995),
Lumpkin e Dess (1996, 2001) e Dess e Lumpkin (2005), Stambaugh, Yu e Dubinsky (2011)

A categorização dos elementos da agressividade competitiva apresentada no Quadro 2 foi feita pelos autores deste estudo, visando melhor situá-los no contexto organizacional. Tal base conceitual constitui um referencial a ser utilizado para estudar a agressividade competitiva em organizações. A presença dos elementos na organização caracteriza a sua agressividade competitiva. Além disso, como a agressividade competitiva pode ser considerada um comportamento, ela pode ser gerenciada. Assim, os elementos apresentados no Quadro 2 podem ser utilizados como base para que uma empresa possa desenvolver práticas de tomada de decisão e políticas que refletem a agressividade competitiva.

Para essa tarefa, é necessário conhecer os elementos mais importantes para determinado setor, segmento, contexto, ou mesmo organização, para então agir no intuito de potencializar, facilitar, estimular esse comportamento nas organizações. Cabe salientar que a agressividade competitiva deveria primar por princípios éticos, segundo os quais poderiam ser questionadas as práticas que busquem, por exemplo, desqualificar o concorrente, embora essa seja uma prática apontada por Dess e Lumpkin (2005).

Assim, a busca por consolidar um conjunto de elementos que caracterizem a agressividade competitiva é um passo na direção de contribuir para o seu desenvolvimento nas organizações. A seguir é apresentado o método de pesquisa utilizado.

\section{Método de Pesquisa}

Esta pesquisa é considerada de natureza exploratória (SELLTIZ et al., 1967). Para sua realização foram utilizados predominantemente dados qualitativos (MASON, 1996). O foco do estudo foram empresas no contexto de setores industriais dinâmicos, especificamente empresas de software e serviços localizadas no estado do Rio Grande do Sul, que se destacam no setor como empreendedoras. Justifica-se a escolha do setor de software tendo em vista sua dinamicidade, devido às rápidas e constantes mudanças tecnológicas, e o crescimento destaque nos últimos anos, superior a diversos setores da economia. (ABES, 2011) 
O estudo empírico iniciou com a identificação de empresas com o perfil definido: empresas de software que se destacam como empreendedoras. Para isso, optou-se por realizar entrevistas com especialistas dirigentes de entidades representativas do setor, que de fato conhecessem as organizações de software do Estado, e assim pudessem indicar quais se enquadram no perfil. Foram contatadas as quatro entidades que hoje lideram e articulam as ações do setor no RS: três entidades setoriais (ASSESPRO-RS, SEPRORGS e SOFTSUL) e uma entidade empresarial (SEBRAE-RS) que tem desenvolvido projetos e ações para fortalecimento do setor por meio do programa setorial de software. A partir do contato com as quatro entidades, foi possível entrevistar dirigentes de três delas (um de cada instituição).

Os especialistas entrevistados atuam no setor há mais de 10 anos e cada deles mantém contato muito próximo com cerca de 200 empresas. Todos são dirigentes das respectivas instituições e têm amplo conhecimento a respeito das empresas e ações do setor. Considerando a larga experiência junto ao setor, o convívio diário com as empresas, além do fato de estarem à frente de entidades que lideram as atividades do setor de software no Estado, entendeu-se que seriam as pessoas mais adequadas a indicar organizações que se destacam como empreendedoras no RS. Esse é um dos principais aspectos que legitimam a escolha das organizações para a realização da pesquisa a partir da indicação dos especialistas. Cooper e Schindler (2003) sinalizam a entrevista com especialistas como adequada no escopo de pesquisa qualitativa exploratória para obter informações de pessoas influentes ou bem informadas a respeito de um determinado contexto.

A partir da apresentação do conceito de orientação empreendedora e suas dimensões para os especialistas, eles indicaram empresas que se destacam como empreendedoras, segundo sua opinião. Além do enquadramento nesse conceito, eles também informaram que tais empresas destacam-se em termos de crescimento anual muito superior à média do mercado. Com isso, foram identificadas 18 empresas de software e serviços (Quadro 3) e seus respectivos dirigentes, também indicados pelos especialistas.

O Quadro 3, além de apresentar as empresas, destaca os dados a respeito de prêmios recebidos por elas ou por seus dirigentes, relacionados a empreen- dedorismo, inovação, $\mathrm{P} \& \mathrm{D}$ e destaque empresarial. Tais dados foram buscados nos web sites das empresas indicadas, no intuito de localizar evidências que reforçassem a indicação dos especialistas. Constatou-se que metade das 18 empresas (e/ou seus executivos) já receberam prêmios relacionados ao tema, o que corrobora sua representatividade no setor no campo do empreendedorismo.

A partir dessa relação, foi realizado contato telefônico e por e-mail com os 18 dirigentes; 13 deles concordaram em participar do estudo, com os quais foi agendado um horário para realização de entrevista. A coleta de dados foi realizada por meio de entrevistas em profundidade com o principal dirigente das empresas, entre os meses de novembro de 2007 e março de 2008. As entrevistas foram conduzidas de forma livre, com duração que variou entre 30 minutos e 1 hora, foram gravadas e depois transcritas. Foi utilizado como guia um protocolo de coleta de dados baseado nos elementos da agressividade competitiva identificados na literatura (MACMILLAN; DAY, 1987; VENKATRAMAN, 1989; COVIN; COVIN, 1991; CHEN; HAMBRICK, 1995; LUMPKIN; DESS, 1996 e 2001; DESS; LUMPKIN, 2005; STAMBAUGH; YU; DUBINSKY, 2011), categorizados em Reação à concorrência, Competição financeira, Competição em negócios e Marketing.

A análise dos dados foi feita de forma qualitativa, usando técnicas de análise de conteúdo. Seguiram-se algumas etapas do modelo para análise de entrevistas não estruturadas proposto por Mattos (2006), sendo elas: a recuperação do momento da entrevista, a análise do significado pragmático da conversação, a montagem da consolidação das falas e a análise de conjuntos. Assim, iniciou-se com a leitura das transcrições e escuta dos áudios, visando sua revisão e compreensão. Os textos transcritos foram organizados segundo as categorias e elementos da base conceitual adotada no estudo. As falas dos 13 executivos foram consolidadas e analisadas, buscando compreender os dados obtidos, procurando identificar neles os elementos da agressividade competitiva, e assim categorizá-los de acordo com os elementos da base conceitual. Uma revisão dos elementos e das categorizações foi realizada pelos pesquisadores (KRIPPENDORFF, 1980), por meio de leitura e releitura, em momentos distintos, com intervalo de tempo, permitindo sua confirmação. 


\begin{tabular}{|c|c|c|c|c|}
\hline & 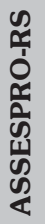 & 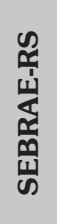 & 峁 & Prêmios/Destaques (ano base até 2008) \\
\hline E1 & & & $\mathrm{x}$ & Certificação CMMI nível 2. \\
\hline E2 & & & $\mathrm{x}$ & $\begin{array}{l}\text { Prêmio Fiergs-Ciergs de Distinção da Indústria } 2006 \text { - Anuário Telecon. Destaque no segmento de } \\
\text { Redes Corporativas } 2008 .\end{array}$ \\
\hline E3 & & & $\mathrm{x}$ & CMMI 2 - MPS.BR - Prêmio Assespro 2004. Prêmio Empresa de Qualidade 2008. \\
\hline E4 & & $\mathrm{x}$ & & Nada consta \\
\hline E5 & $\mathrm{x}$ & & & Nada consta \\
\hline E6 & $\mathrm{x}$ & & & $\begin{array}{l}\text { ISO9001 - CMM } 1 \text { e 2. Melhor Performance Nacional em Tecnologia voltado ao Mercado Segurador. } \\
\text { Exame Melhores e Maiores (2008 - Rentabilidade). Melhor empresa no setor de TI - Gazeta Mercantil } \\
\text { - Revista Balanço Anual ( } 32^{\text {a }} \text {. Edição). Pesquisa Info Marcas - Campeã pelo } 4^{\circ} \text { ano consecutivo na } \\
\text { Categoria Integração, Desenvolvimento e Fábrica de Software (2008). }\end{array}$ \\
\hline E7 & & & $\mathrm{x}$ & Prêmio Assespro 2004. \\
\hline E8 & $\mathrm{x}$ & & & Nada consta \\
\hline E9 & $\mathrm{x}$ & & $\mathrm{x}$ & Prêmio Assespro 2006 - ISO9001. \\
\hline E10 & & $\mathrm{x}$ & & $\begin{array}{l}\text { Medalha no Prêmio Qualidade RS 2008. Empresa Destaque TI } 2008 / 2009 \text { Assespro-RS. } \\
\text { Melhores Empresas para se trabalhar em TI e Telecom do país ( } 24^{\circ} \text { lugar). Empresa de TI com maior } \\
\text { pontuação do Programa Gaúcho de Qualidade e Produtividade (2007) }\end{array}$ \\
\hline E11 & $\mathrm{x}$ & & & Troféu Destaque Gaúcho Empresarial 2008. Prêmio revenda SolidWorks América Latina 2007. \\
\hline E12 & & & $\mathrm{x}$ & $\begin{array}{l}\text { Prêmio Assespro 2002. Prêmio FINEP de Inovação } 2008 \text { Região Sul. Certificado e medalha de } \\
\text { Responsabilidade Social (Assembléia Legislativa do RS - 2008). Campeã nacional (CNI 2008) } \\
\text { na categoria inovação e competitividade - médias e grandes empresas. Troféu Ouro do Prêmio } \\
\text { Qualidade RS (2008). Certificado Responsabilidade Social da Revista Expressão Categoria Clientes } \\
\text { (2007). Diploma Empresa Destaque do Sistema de Avaliação } 2006 \text { - Comitê Setorial Qualidade- } \\
\text { RS - TI. Prêmio Engenheiro } 2006 \text { na área privada (Presidente - 2006). Prêmio Luciano Sighieri de } \\
\text { Desenvolvimento Empresarial e Tecnológico - ISA SHOW (Presidente). }\end{array}$ \\
\hline E13 & $\mathrm{x}$ & $\mathrm{x}$ & & Nada consta \\
\hline E14 & & $\mathrm{x}$ & & Nada consta \\
\hline E15 & & $\mathrm{x}$ & & Nada consta \\
\hline E16 & & $\mathrm{x}$ & & Nada consta \\
\hline E17 & $\mathrm{x}$ & & $\mathrm{x}$ & Nada consta \\
\hline E18 & & & $\mathrm{x}$ & Nada consta \\
\hline
\end{tabular}

Quadro 3: Lista das empresas empreendedoras por indicação dos especialistas

Fonte: Elaborado pelos autores com base nas entrevistas e nos web sites das empresas (dados de 2008)

A seguir, é apresentada a análise dos resultados do estudo. 


\section{Agressividade Competitiva: A EXPERIÊNCIA DOS EXECUTIVOS}

Esta seção apresenta a análise dos resultados do estudo, com destaque a trechos de depoimentos dos 13 executivos entrevistados, que retratam a agressividade competitiva no que se refere à Reação à concorrência, Competição financeira, Competição em negócios e Marketing. Na análise realizada não se buscou quantificar ou verificar a intensidade com que os elementos da agressividade competitiva ocorrem nas empresas, mas identificar a sua presença e ilustrar práticas a partir da experiência dos executivos.

Inicialmente, o Quadro 4 caracteriza as empresas que participaram do estudo, que são consolidadas no mercado, com tempo de atuação entre 6 e 25 anos, e localizadas na região metropolitana de Porto Alegre (RS). Os entrevistados são todos do sexo masculino, ocupando cargos de direção; à exceção do entrevistado da Empresa 6, os demais têm participação societária na empresa.

\begin{tabular}{|c|c|c|c|c|c|c|}
\hline EMPRESA & ENTREVISTADO & N. Func. & PORTE* & $\begin{array}{l}\text { N. } \\
\text { UNID }\end{array}$ & Atuação & Negócio \\
\hline E1 & Superintendente & 300 & Médio & 3 & Nacional & Produção de softwares e serviços de TI \\
\hline E2 & Presidente & 100 & Médio & 9 & Internac. & Desenvolve produtos de telecomunicações \\
\hline E3 & Presidente & 85 & Pequeno & 2 & Nacional & Promove serviços e soluções em TI \\
\hline E4 & Diretor-presidente & 55 & Pequeno & 2 & Nacional & Desenvolve aplicação p/marketing de precisão \\
\hline E5 & Diretor comcial & 10 & Micro & 3 & Nacional & Desenvolve software $\mathrm{p} /$ computação móvel \\
\hline E6 & Gerente de negóc. & 5000 & Grande & 100 & Internac. & Consultorias estratégicas de TI \\
\hline E7 & Diretor & 26 & Pequeno & 5 & Nacional & $\begin{array}{l}\text { Assessoria e desenvolvimento de software } \mathrm{p} / \\
\text { saúde }\end{array}$ \\
\hline E8 & Diretor & 34 & Pequeno & 2 & Nacional & Desenvolve web sites e sistemas $\mathrm{p} /$ turismo \\
\hline E9 & Diretor-presidente & 250 & Não infor. & 3 & Internac. & Serviços e soluções de infraestrutura de TI \\
\hline E10 & Diretor & 350 & Médio & 26 & Nacional & Desenvolve ERP para empresas \\
\hline E11 & Diretor & 100 & Médio & 7 & Nacional & $\begin{array}{l}\text { Desenvolve software } \mathrm{p} / \text { projetos mecânicos e } \\
\text { elétricos }\end{array}$ \\
\hline E12 & Presidente & 200 & Médio & 11 & Internac. & Soluções automação e integração sistemas \\
\hline E13 & Diretor & 96 & Pequeno & 1 & Estadual & Soluções digitais em comunicação e TI \\
\hline
\end{tabular}

* porte segundo faturamento anual: microempresa até $\mathrm{R} \$ 1.200 .000,00$; pequeno porte entre $\mathrm{R} \$ 1.200 .000,00$ e $\mathrm{R} \$ 2.400 .000,00 ;$ médio porte entre $\mathrm{R} \$$ 2.400.000,00 e $\mathrm{R} \$ 48.000 .000,00$; grande porte superior a $\mathrm{R} \$ 48.000 .000,00$.

Quadro 4: Caracterização das empresas cujos executivos foram entrevistados

Fonte: Elaborado pelos autores deste artigo (dados de 2008)

\subsection{Reação à Concorrência}

A reação à concorrência implica monitoramento de mercado. Para reagir, antes é necessário conhecer as ações da concorrência (LUMPKIN; DESS, 2001), retratando a conscientização tratada por Chen (1996) e Stambaugh et al. (2009). "Eu tô aprendendo muito com o concorrente. Tem que ficar de olho no que eles fazem de certo e de errado", afirma o Executivo 10, ilustrando uma prática comum entre os 13 entrevistados. Estratégias que contribuem para a aprovação de propostas, formato de venda, níveis de serviços, tipo de atendimento, entre outros, são algumas ações da concorrência observadas pelas empresas. Por vezes, para monitorar o mercado são utilizadas dinâmicas mais elaboradas, com a contratação de pesquisas para a realização de análise de mercado e avaliação da concorrência.

$\mathrm{O}$ mercado de atuação de pelo menos metade das 13 empresas é altamente competitivo, com concorrentes de grande porte e multinacionais. Aliado a isso, uma particularidade do setor de software são as rápidas e constantes mudanças tecnológicas que 
tornam o setor extremamente dinâmico. Os softwares estão sempre evoluindo, as novidades precisam ser muito bem testadas, $e$ isso impacta na estrutura. Isso também implica ser mais agressivo do que há alguns anos atrás, devido à evolução tecnológica. Se a concorrência lança um produto ou serviço, é necessário lançar similar para não perder parcela de mercado e continuar atendendo clientes mais fortes, por vezes estratégicos para as empresas. Isso retrata a capacidade (CHEN, 1996) de fazer contrataques competitivos. "Como nós queremos ser grandes, temos que fazer como as empresas grandes. [...] trabalhar com números do mercado e do concorrente também é fundamental [...]", relata o Executivo 10.

Outro exemplo aparece nesse trecho da fala do Executivo 6, retratando ações em decorrência da observação da concorrência: "É fundamental estar presente em grandes feiras e com um posicionamento muito forte. Esse foi um dos nossos aprendizados observando grandes players". (Executivo 6)

Chama atenção o desenvolvimento de ações para expansão de mercado, retratando a estratégia de multiplicação apontada por Venkatraman (1989). As 13 empresas pesquisadas são destaque no setor em crescimento no Estado do RS. Isso parece ser explicado pelas ações desenvolvidas com esse intuito, buscando ocupar espaços importantes no mercado. Entre elas, estão a abertura de filiais, a estruturação de franquias, a abertura de capital, o desenvolvimento de novas unidades via modelo de parcerias.

[...] eu percebi que a gente tinha um excelente produto e tinha uma capacidade de venda limitada. Então fomos buscar parceiros que nos ajudassem a ganhar o Brasil. [...] hoje temos diversas unidades no País pelo sistema de parceira, também temos uma filial em Brasília, que é um modelo novo que estamos experimentando agora. [...] nos últimos dez anos adquirimos umas quatro empresas pelo modelo de parceira: a empresa tinha o produto, tinha o ERP que não conseguia mais dar continuidade e tinha uma bela carteira de cliente, e a gente fez uma troca de carteira de clientes por produto. [...] nós temos uma rede de parceiros internacionais também, que começou a ser formada em 1998. (Executivo 10)

\subsection{Competição em Negócios}

Ações diversas retratam a competição em negócios nas empresas estudadas. Uma das principais tendências observadas no setor de software, com base nas entrevistas e em outras fontes sobre o setor, é a necessidade de união das empresas para seu fortalecimento (ROSELINO, 2007; ABES, 2010). Isso tende a resultar num número crescente de fusões e aquisições nos próximos anos. Essa realidade é ilustrada na fala de um entrevistado, cuja empresa já iniciou um processo de aquisições de outras empresas.

[...] um tempo atrás eu estava num evento onde um palestrante disse: "Hoje o posicionamento das empresas de TI são só dois: ou elas são os predadores, ou elas são a noiva". Ou a empresa será levada por alguém ou ela está entre as empresas que vão começar a incorporar e se fortalecer. Eu acho que a nossa empresa se posicionou muito bem naquele momento, hoje a gente vê os reflexos disso e as empresas têm que ir nessa caminhada. O mercado está se afunilando, as empresas que só atingiam grandes contas hoje já estão pegando empresas de menor porte. Vai chegar uma hora que não vai ter mercado e eles vão ter que vender suas empresas. (Executivo 7)

Seguindo essa tendência, observa-se que as empresas estão indo ao encontro do que o mercado está sinalizando, resultando no desenvolvimento de novas formas organizacionais (GLEGG; HARDY, 1998), por meio de fusões, aquisições, incorporações, associações entre empresas, alianças, etc., para a realização de ações conjuntas. Essas iniciativas passam antes por decisões de manter-se no mercado ou crescer, fato ilustrado nesse trecho de entrevista.

A gente ficava pensando assim: 'Por que eu não posso oferecer meus serviços para a Petrobrás, para a Vale do Rio Doce?' Porque eu não tenho tamanho, não tenho isso e aquilo, eles vão dizer: 'só compro da IBM, Oracle, DELL, Microsoft'. [...] A fusão de 2003 nos deu outro potencial, a gente começou a ser reconhecido de forma bem mais robusta. E hoje a gente tem contratos com grandes empresas. (Executivo 3) 
Também foi identificada uma situação onde a empresa foi criada a partir de um modelo de consolidação de empresas, devido à oportunidade identificada no mercado. E isso é encarado como uma estratégia da empresa para crescimento no mercado, de uma empresa que iniciou da união de cinco pequenas empresas, e aos poucos vem crescendo buscando agregar outras: "Éramos cinco, incorporamos uma sexta operação e temos em negociação três ou quatro incorporações [...]", fala o Executivo 13. Essas iniciativas, além de serem oportunidades de crescimento $e$ fortalecimento da empresa promotora, agregando novas competências, também contribuem para o fortalecimento do setor de software, possibilitando uma melhoria em aspectos mais frágeis nas empresas envolvidas, como ilustrado nesse trecho.

[...] Quando a gente chamava um parceiro pra trabalhar junto em alguma coisa, funcionava um pouco melhor tecnicamente, resultando numa entrega ao cliente com mais consistência. Então a gente começou a ver que a composição era interessante, um tinha o perfil de vender a solução, mas não conseguia entregar, o outro mais técnico. Pra contratar um profissional pra área financeira eu não tinha condições, mas se nós juntássemos dois ou três, dividíssemos o custo daquela pessoa, teríamos alguém olhando com qualidade nossa gestão financeira. (Executivo 13)

Na mesma linha de atuação, iniciativas para internacionalização das empresas foram identificadas nas entrevistas, também retratando uma tendência no setor (ROSELINO; DIEGUES, 2006), vista como de grande relevância. Há exemplos de consórcio de exportação, de parcerias com emprsesas estrangeiras para atuação no exterior, de instalação de unidades em outros países. "Nós estamos vendo isso [consórcio] como uma importante alternativa para nós termos outros mercados e outras oportunidades de negócios. Somos empresas que são concorrentes em alguns aspectos, que são apoiadoras entre si, que tem um objetivo de atender um mercado que todas juntas conseguem mostrar mais potencial que cada uma individualmente", ilustra o Executivo 3, um dos envolvidos na organização dessa iniciativa.

Outra situação diferenciada é a de atuação no exterior por meio de home-offices, sem unidades físicas. O Executivo 8 relata essa situação, que iniciou com a realização de parcerias com empresas internacionais para atender a determinada necessidade da empresa estrangeira junto a seus clientes. Após a realização de grande projeto piloto, eles foram homologados e recomendados em diversos mercados. A partir daí foram criados os escritórios virtuais.

Merece destaque também um depoimento que relata a constituição de aliança entre empresas de diferentes países, que está resultando em uma série de ações conjuntas, entre elas o desenvolvimento de um produto global, com características aplicáveis a diferentes países.

[...] A gente tá fazendo um projeto mundial, estamos com uma empresa da Índia e uma empresa da República Tcheca. São 3 empresas fazendo um produto, ele vai ser vendido nesses três continentes. Isso é uma adaptação nossa, pra concorrer com uma Siemens que tem um laboratório lá na Alemanha. [...] Eu tinha um amigo indiano e eu falei pra esse cara "vamos fazer uma aliança e vamos ver o que a gente sabe fazer juntos". [...] vimos que a maior área que a gente podia fazer algo era na área de $P \& D$, porque os outros produtos eram todos muito locais, e nós não tínhamos um produto global. [...] um produto de primeiríssima linha, fantástico, não tem nenhum limite, eu posso produzir na China, usando melhores tecnologias. (Executivo 12)

Embora essas iniciativas de internacionalização sejam muito importantes, também é destacado que o mercado brasileiro ainda tem muito espaço para produtos diferenciados e de alta qualidade, espaço atualmente ocupado pelos produtos importados. " $\mathrm{Eu}$ posso chegar aos meus primeiros cem milhões de dólares trabalhando aqui, não precisa exportar tanto, mas precisa ter um produto dentro do Brasil com a mesma qualidade dos que são importados", exemplifica o Executivo 13. Para enfrentar essa concorrência, que envolve competir com grandes líderes, é necessário trabalho focado, olhar o mercado e investir em melhorias.

O uso de métodos de competição não convencionais (LUMPKIN; DESS, 1996; CHEN; 1996) pode ser ilustrado em trechos de dois depoimentos. Um dos entrevistados fala sobre a realização de projetos maiores com pelo menos duas frentes de ação, visando mais chances de sucesso; outro relata sobre estratégia diferenciada para participação em feiras. 
A gente desenvolveu um projeto de ensino a distância, com duas frentes. Se as duas derem certo, nós vamos seguir as duas. A chance das duas darem errado é quase zero. [...] são projetos que se preocupam muito com planejamento, eu já sei quanto tempo eu vou ter que gastar, e a partir de que momento eu vou ter lucro, $e$ se tudo falhar eu vou ter a outra alternativa. Empresa grande faz isso, de ter sempre uma alternativa. E a gente tem conseguido sucesso assim. (Executivo 10)

[...] a gente descobriu que em algumas feiras não pode ir com bandeira do Brasil, não pode. No ano passado nós fizemos uma exposição em Las Vegas já com empresas com o nosso nome, mas como chinesa. Por incrível que pareça dá mais resultado. [...] inclusive nos EUA, a gente vai entrar com a nossa empresa como uma empresa americana. Isso são detalhes que tu tem que pesquisar, senão tu vai gastar um monte de dinheiro pra entrar no mercado americano e tu não entra. [...] $O$ americano quer saber que tá comprando de uma empresa americana que tá aqui, que é responsável pelo produto, não interessa onde ele é fabricado. (Executivo 2)

Ao mesmo tempo em que se observa o desafio aos líderes da indústria (LUMPKIN; DESS, 1996) na realidade pesquisada, há também o relato de um caso que retrata a desqualificação de competidores (COVIN; COVIN, 1990; DESS; LUMPKIN. 2005) focando na superioridade do produto.

[...] naquilo que a gente se propõe a fazer temos que ser o melhor. Em alguns casos nós conseguimos desqualificar o número um do mundo por mostrar que o desempenho que ele estava apresentando não correspondia ao mínimo que o cliente precisaria. (Executivo 4)

Em outro trecho de sua entrevista o mesmo executivo fala do enfrentamento de grandes empresas no momento de uma concorrência, retratando ações desafiadoras e a motivação para superar rivais (CHEN, 1996):

[...] focamos a superioridade do nosso produto, e não importa com relação a quem: 'ah, eu sou o número um do mundo pela Meta Group, pela Forrester'. 'Ok, vamos fazer um teste piloto, mostrar pra você [cliente]. Bota na pista, quem ganhar é o melhor'. Medalha antes da competição a gente acha que não é bom para o mercado. Nós sempre provocamos este tipo de desafio. (Executivo 4)

O benchmarking competitivo também é identificado nas entrevistas. Ele é usado para comparar as operações de uma organização às de seus concorrentes (KRÜCKEN-PEREIRA; DEBIASI; ABREU, 2001). Algumas evidências a esse respeito são identificadas nas entrevistas e exemplificadas nos trechos a seguir.

[...] naquilo que a gente não pode estar à frente, a gente está associado com alguém que pode estar à frente. A gente pega o que a Microsoft está fazendo, compara com a IBM, com a Symantec, e se dá conta que o mercado está indo pra lá. Os dez bilhões que a Microsoft investe em P\&D por ano nós vamos aproveitar. (Executivo 9) [...] a gente começou a identificar grandes players da área de ERP genérico, não da área de saúde. O que esses ERPs estavam trabalhando, suas campanhas de marketing, o posicionamento perante o mercado, e começamos a mudar o foco. Começamos a ver que os players pra nós não eram os nossos concorrentes diretos, mas é o segmento de ERP, por exemplo. (Executivo 7)

Além do benchmarking, o trecho relacionado à fala do Executivo 4, a seguir, também demonstra a opção por altos investimentos no desenvolvimento de produtos, em detrimento de investimentos em canais comerciais, priorizando assim a qualidade em produtos e serviços.

A gente quer disputar com empresas que sejam benchmarks, com os melhores, a gente não quer vender qualquer serviço a qualquer preço. Então nós estabelecemos já um patamar de partida, enfrentar desde IBM, SAP. [...] Se alguém erra quando compra IBM, quando compra ORACLE, quando compra Microsoft, erra tentando comprar um big player mundial. Se alguém erra comprando daquela empresa lá de Porto Alegre, não tem muita chance de explicar. (Executivo 4)

A participação em feiras com o propósito de ser um captador é destacada: "[...] eu gosto de ir a feiras fora do país porque daí eu vou como 'chapa branca', daí eu sento, assisto, pergunto. Em feiras no Brasil não adianta ir, porque eu sou carta marcada já e muitos dos que trabalham comigo também." (Executivo 11). Ele também fala sobre troca de experiências com empresas 
no exterior: "Eu tenho ido visitar empresas similares à nossa tanto na Europa como nos EUA, e eu tenho contato com pessoas e troco figurinhas com elas".

Outro executivo destaca a importância das feiras nacionais e no exterior para realização de benchmarking. "Faz alguns anos que estamos planejando como ir pro mercado externo. Então como é que tu vai? Tu vai chegar no país, vai bater, aonde tá o cliente? E as feiras tem sido uma ferramenta pra nós" (Executivo 2). Ele continua: "[...] eu vou há 15 anos pra Ásia então a gente vê como as coisas funcionam, no ano passado eu estive na Coreia [...]. Nós participamos de bastante feiras internacionais, na Alemanha, nos Estados Unidos, Hong Kong, Espanha, Argentina, a gente vai como expositor e também como visitante, a gente vai ver o que está acontecendo" (Executivo 2). O Executivo 8 complementa:

[...] nós participamos das principais feiras de nosso segmento, nos Estados Unidos, na Espanha, na maior feira que ocorre anualmente em Madrid. [...] a gente participa de congressos de tendências, pra estar olhando pro mercado, vendo o que grandes players fazem e acompanhar o que vem de novo. (Executivo 8)

\subsection{Marketing}

A maior parte dos executivos entrevistados fala sobre a realização de um marketing focado no mercado de atuação. Diversas ações são ilustradas a respeito: a participação em feiras profissionais; o desenvolvimento de casos de sucesso para revistas especializadas ou para o meio técnico, com base em projetos bem sucedidos; a utilização de informativos da empresa para o público direto; entre outras formas. "Temos procurado transmitir as experiências que a gente tem tido com outras verticais. Assim, o cliente não lê a news só por ler, ele leu pra ver 'ah, vocês fizeram assim lá naquele mercado'. Aí outras empresas lêem e fazem a mesma coisa, é uma lógica que a gente adotou e tem dado certo". (Executivo 9)

Também é realizado um marketing institucional visando à projeção da empresa no mercado, o fortalecimento da imagem, bem como a inserção da marca e da empresa em alguns segmentos econômicos de interesse. Para empresas que tem atuação em algum segmento mais específico, isso fica mais evidente.
[...] como temos uma vertical só na área da saúde, todo o nosso trabalho de marketing $e$ mídia é direcionado. Além do posicionamento no teu segmento, tu tem que ter uma visibilidade fora do segmento, porque ali é que surgem outros projetos. Hoje temos uma assessoria de imprensa que atua só na parte de estruturação de marketing: eventos, jornais, reportagens focadas no segmento, etc. (Executivo 7)

Ainda no que se refere à imagem, um entrevistado fala da sua importância para assegurar a credibilidade junto ao cliente: "O fato de eu estar na FIERGS, de eu estar na ABIN... essas instituições não vão deixar de existir. Tu usa acordos com o BNDS, acordos com o governo; o balanço social, a tua imagem de responsabilidade, essa é uma porta importante também" (Executivo 12). Segundo ele, num mercado com a presença de grandes empresas e multinacionais, conquistar clientes e fazer negócios não é tarefa fácil; recorrer à imagem dos dirigentes, às relações institucionais, às ações de responsabilidade social, aos acordos com instituições e governos tem sido a prática utilizada nessa empresa.

Outra forma de ser mais agressivo em marketing pode ser baseada na estratégia comercial, especialmente em contextos onde os produtos são muito similares. O contraponto dessa situação, contudo, é a necessidade de maior agressividade comercial, fato relatado em algumas entrevistas. Por vezes, há dificuldade de alocar profissionais, com adequada competência comercial e técnica, devido à característica técnica do negócio, o que exige essa complementariedade de competências do profissional que atua na linha de frente. Nesse caso, seria importante o desenvolvimento de força de vendas mais agressiva.

\subsection{Competição Financeira}

Corroborando a literatura, foram relatadas ocorrências de competição financeira nas empresas pesquisadas, como negociações que, mesmo comprometendo o fluxo de caixa ou a rentabilidade, foram realizadas, tendo em vista o interesse da empresa em um cliente novo, ou para não perder uma negociação ou um cliente já conquistado, ou para não perder posição ou parcela do mercado. Como afirmou o Executivo 4, "Se a gente está muito a fim de ter aquele cliente, a gente paga pra ter". 
Mas também existem situações em que as empresas são a referência no mercado e por esse motivo a competição financeira definitivamente não tem lugar ou é muito rara. Nesses casos, a concorrência adota preços muito baixos ao competir com essas empresas. Um dirigente ilustra essa realidade, reforçando, por exemplo, a qualificação da equipe, que é constituída de profissionais especializados, com formação acadêmica, que atuam há tempo na empresa, e consequentemente são uma mão de obra mais cara. "[...] muitos dizem: 'ah, mas o treinamento do teu concorrente é a metade do teu preço'. 'Tá bom, tu quer pagar a metade tu pode pagar, mas eu vou te mandar um estagiário e não um engenheiro". (Executivo 11)

Entretanto, num contexto geral, extrapolando as empresas pesquisadas, a competição financeira parece ser uma prática comum no mercado de software. Um dos motivos pode ser o fato do software ser fortemente baseado em serviços, o que implica um cálculo de custo e preço diferente do de um produto físico. Naturalmente existe uma estrutura de formação de preços para o serviço, mas isso propicia certa flexibilidade de negociação. E talvez por esse motivo, também fica nítida a prática de preços muito abaixo do mercado, fato mais comum onde há menor capacitação em gestão ou falha da gestão financeira, por vezes incentivado por uma parcela de clientes que não é educada a pagar um preço justo, gerando uma verdadeira guerra de preços e espaço para negócios não lícitos. Isso é ilustrado nessa fala.

A informática é um mercado muito fértil para empresas não muito éticas, para desonestidade, porque tu vende um projeto. Depois que o software estiver pronto o cara vê o que comprou. Então tá muito na empresa saber se está ou não iludindo quem tá comprando. Ele sabe que o que ele tá vendendo ele não vai entregar, que não vai ser aquilo que o cara tá esperando, porque ele tá fazendo alguma coisa para poder baixar muito o preço, e ele sabe que tá comprometendo a qualidade. Ele vai ganhar esse dinheiro e quando entregar o projeto o cara vai ver que não deu, mas não tem mais o que fazer, vai ter que pagar de novo, pra ele ou pra outro. (Executivo 1)

Outro executivo corrobora com essa realidade em trecho de sua entrevista.
Hoje nós fechamos um negócio por 20 mil. Tem concorrente vendendo por 2 mil. Mas ele vale os 20 mil, este valor é justo. E como é que o cara vende por 2 mil? Ele faz a conta que em um mês de trabalho ele entrega aquilo, ele trabalha sozinho e julga que este valor de salário é bom pra ele. Mas ele não fez a conta do imposto, ele não vai emitir nota fiscal, ele não está pagando previdência privada, INSS, plano de saúde, ele só fez a conta do dinheiro que entra. (Executivo 13)

\section{Agressividade Competitiva em EMPRESAS DE SOFTWARE: DISCUSSÕES}

O estudo junto aos 13 executivos permitiu identificar práticas organizacionais de agressividade competitiva nas empresas de software foco do estudo. Cotejando a base conceitual sobre o tema com o estudo empírico, pode-se afirmar que os elementos da base conceitual repercutem nas empresas, corroborando com a literatura a respeito.

Constatou-se que existe um forte olhar sobre a concorrência nas empresas pesquisadas, no intuito de conhecê-la para aprender e reagir, retratado na categoria Reação à concorrência. Essa observação do mercado na busca de informações dá subsídios para que as empresas se movam em função das ações dos concorrentes.

Com relação à Competição em negócios, há diversas situações evocadas pelos executivos que retratam uma postura no sentido de reagir às tendências do mercado, e até mesmo usar métodos de competição não convencionais. Talvez essa seja a categoria da agressividade competitiva que mais se evidencia junto aos entrevistados. Aqui também merecem destaque a Atuação por meio de novas formas organizacionais $e$ as Ações de internacionalização, ambos representando tendências no setor e importantes iniciativas já em desenvolvimento entre as empresas pesquisadas. Destaca-se um posicionamento agressivo e competitivo, tendo como exemplo a utilização de ações para desqualificar os competidores, mas tendo como foco alta qualificação da empresa como diferencial perante a concorrência. Também há realização de Benchmarking competitivo, com identificação de boas práticas e ten- 
dências do mercado, e adoção de práticas utilizadas por competidores de sucesso.

No que se refere ao Marketing, há um indicativo mais forte no sentido de uso de marketing oportuno de novos produtos ou tecnologias, voltado para um público mais direcionado, e de uso da imagem para fortalecimento perante o mercado; com menor incidência é manifestado o investimento agressivo em marketing. Talvez nessa categoria haja mais espaço para o desenvolvimento de ações visando maior agressividade em marketing, tendo em vista as poucas situações que se destacaram nas falas dos executivos.

Finalmente, sobre a Competição financeira, a busca por posição no mercado à custa de fluxo de caixa ou rentabilidade e com ações de redução de preço ocorre somente em situações em que realmente se faz necessário, não sendo a diretriz da maioria das empresas. Contudo, também é evidenciado que existe uma parcela do mercado de software que vive uma verdadeira guerra de preços, com práticas muito abaixo da normalidade, com margem para operações ilícitas e que acabam prejudicando o mercado.

Embora não fosse objetivo deste estudo quantificar ou verificar a intensidade com que os elementos da base conceitual se manifestam nas organizações, sobressaem alguns que podem ser destacados em termos de práticas mais evidenciadas nas entrevistas, conforme apresentado no Quadro 5.

\begin{tabular}{|c|c|c|}
\hline Categorias & Práticas mais difundidas & Práticas menos difUNDIDAS \\
\hline Reação à concorrência & $\begin{array}{l}\text { Mover-se em função das ações dos concorrentes. } \\
\text { Empresa muito agressiva e intensamente competitiva. }\end{array}$ & $\begin{array}{l}\text { Responder agressivamente às ações dos } \\
\text { concorrentes. }\end{array}$ \\
\hline Competição em negócios & $\begin{array}{l}\text { Uso de métodos de competição não convencionais: } \\
\text { atuação por meio de novas formas organizacionais e } \\
\text { ações de internacionalização. } \\
\text { Métodos de benchmarking: copia práticas de negócios } \\
\text { ou técnicas de competidores de sucesso. }\end{array}$ & $\begin{array}{l}\text { Postura agressiva para combater tendências } \\
\text { da indústria que podem ameaçar a } \\
\text { sobrevivência ou posição competitiva. } \\
\text { Postura antiética: tipicamente adota uma } \\
\text { postura muito competitiva, desqualificando } \\
\text { os competidores. }\end{array}$ \\
\hline Marketing & $\begin{array}{l}\text { Faz marketing oportuno de novos produtos ou } \\
\text { tecnologias. }\end{array}$ & Investimentos agressivos em marketing. \\
\hline Competição financeira & $\begin{array}{l}\text { Busca posição no mercado à custa de fluxo de caixa ou } \\
\text { rentabilidade. } \\
\text { Reduz preços para aumentar participação no mercado. }\end{array}$ & Coloca preços abaixo da competição. \\
\hline
\end{tabular}

Quadro 5: Difusão das práticas de agressividade competitiva entre as empresas representativas do setor de software Fonte: Elaborado pelos autores deste artigo

As práticas da agressividade competitiva classificadas como menos difundidas nas empresas foco do estudo podem sinalizar oportunidades de realização de melhorias visando o fortalecimento desse comportamento nas empresas pesquisadas. Salienta-se, contudo, a presença de uma postura antiética entre as práticas menos difundidas, a qual se questiona. Um olhar mais atento de cada empresa sobre o Quadro 5 pode facilitar a identificação de elementos que no caso em particular mereceriam ser potencializados.

Um aspecto que merece atenção é o quanto cada elemento é importante para o desenvolvimento de uma maior agressividade competitiva. Em geral, a presença do conjunto de práticas em maior intensidade na empresa representa uma maior agressividade competitiva. Contudo, dependendo de características do mercado, setor, segmento específico e mesmo da empresa, talvez algumas práticas sobressaiam outras em termos de importância. Assim, a compreensão da realidade vivida por cada empresa e a reflexão a respeito pelos profissionais envolvidos, tendo como base o conjunto de práticas da agressividade competitiva, pode trazer contribuições no intuito de direcionar esforços ao desenvolvimento de práticas eventualmente mais relevantes em determinado contexto.

Outra abordagem que convém ser tratada é a de Stambaugh et al. (2009), que propõe três construtos que podem ser utilizados para desenvolver internamente na empresa práticas e políticas que refletem a agressividade competitiva: consciência rival, motivação para superar e capacidade de ação. No contexto estudado, a consciência rival é claramente identificada no 
conjunto das 13 empresas à medida que existe constante busca de informações sobre as ações do mercado e da concorrência. Isso pode ser exemplificado nas participações em feiras, na avaliação de concorrentes diretos e indiretos, na identificação de pontos positivos e negativos dos competidores, na atenção constante a tendências tecnológicas e lançamento de novos produtos, entre outros. A motivação para superar destaca-se em alguns depoimentos que evidenciam ações de superação de concorrentes, a exemplo de ganho de concorrências, de reação rápida quando do lançamento de novos produtos e serviços pela concorrência, de ações para desqualificar a concorrência, entre outras. A capacidade de ação também é evidenciada à medida que as empresas reagem às ações da concorrência, retratando a existência de recursos para tal. Aqui também podem ser destacadas as ações de união entre empresas, iniciativas conjuntas, ações de internacionalização, que denotam a existência de recursos disponíveis para iniciar e responder às ações da concorrência, seja individual ou coletivamente.

De certa forma, esses construtos apontados por Stambauch et al. (2009) perpassam o conjunto de práticas da agressividade competitiva resultante deste estudo (Quadro 5), à medida que: a consciência rival é necessária para identificar ações da concorrência para então agir; a motivação para superar retrata a voluntariedade para ser agressivo no mercado, superando a concorrência; e, a capacidade de ação representa as condições que a empresa tem de agir no mercado e reagir à concorrência.

Assim, as empresas que desejarem potencializar ou desenvolver a agressividade competitiva podem ter como orientação o conjunto de práticas e categorias apresentado no Quadro 5. De forma complementar, uma reflexão a respeito da consciência rival, da motivação para superar e da capacidade de ação também pode contribuir para a compreensão da agressividade competitiva e da identificação de práticas a serem potencializadas.

\section{Considerações Finais}

Ao final deste estudo sobre a agressividade competitiva, importante dimensão da orientação empreendedora de uma organização, cabem algumas considerações sobre a sua repercussão nas empresas e sobre o conjunto de práticas resultante do estudo.

A dinamicidade do setor de software, os movimentos do mercado, as mudanças tecnológicas constantes, os grandes atores do mercado, são alguns elementos que exigem uma atitude agressiva das empresas para manutenção e ganho de mercado diante da concorrência. Nesse contexto, que retrata a realidade das empresas estudadas, a agressividade competitiva se mostra como um comportamento relevante, e é identificada por meio de um conjunto de práticas, algumas mais difundidas no contexto estudado, outras menos difundidas.

A evidência das práticas de agressividade competitiva nas entrevistas dos executivos permitiu confirmar os elementos da base conceitual consolidada da literatura, adotada para realização do estudo, corroborando a teoria na prática organizacional. Assim, considera-se que a primeira contribuição deste estudo é o conjunto de práticas resultante (Quadro 5), proposto a partir da literatura, confirmado e enriquecido na prática organizacional. Embora esse conjunto de práticas caracterize a agressividade competitiva nas empresas cujos executivos foram entrevistados, retratando a realidade no contexto estudado, ele tem potencial para orientar ações no intuito de desenvolver a agressividade competitiva em empresas do setor de software e serviços, uma vez que a presença dos elementos retrata esse comportamento na empresa.

Uma segunda contribuição deste estudo se dá à medida que são apresentadas práticas efetivas sobre a agressividade competitiva retratando experiências dos executivos entrevistados. Tais aspectos podem ser úteis como conhecimento e aprendizado sobre o setor de software, uma vez que eles decorrem da vivência de gestão dos executivos à frente de empresas consideradas referência no setor.

Por fim, uma vez que a base conceitual sobre a agressividade competitiva foi cotejada com a prática efetiva das empresas e enriquecida com os elementos consolidados e com as categorias agregadoras, ela pode ser considerada mais consistente, com interessante potencial de contribuição para o meio acadêmico $e$ para a prática gerencial. Espera-se, com isso, também contribuir para o debate sobre ações de estímulo à agressividade competitiva com ética e ao empreendedorismo em empresas de software. 
Alguns limites metodológicos do estudo devem ser considerados. Não se recorreu a uma técnica mais apurada de quantificação que pudesse embasar, na sequência, um procedimento mais específico de validação. Também não se recorreu a instrumentos de triangulação, mas cabe considerar que os dados coletados junto aos executivos foram ricos, honestos, espontâneos, profundos de significado. E ainda, a subjetividade na condução do processo de entrevista, análise dos dados e elaboração dos resultados. Contudo, esforço de estudo, de leitura e de reflexão foi feito na tentativa de minimizar esses aspectos, tendo estabilidade na interpretação, nas diferentes leituras realizadas pelos pesquisadores, por ocasião da interpretação dos resultados.

Como sugestões de pesquisas futuras, o conjunto de práticas resultante deste estudo pode ser utilizado para estudar outros setores, onde, eventualmente, uma configuração mais direcionada para o setor específico pode resultar. Também se sugere o uso do conjunto de elementos para a realização de pesquisa quantitativa com empresas de software, com um universo de abrangência nacional. Outra possibilidade seria escolher uma organização notadamente empreendedora para realizar estudo longitudinal em profundidade, com triangulação de dados.

\section{REFERÊNCIAS}

ABES - Associação Brasileira das Empresas de Software.

Mercado brasileiro de software: panorama e tendências, 2011. 1. ed. São Paulo: ABES, 2011.

Disponível em: <http://www.abes.org.br/UserFiles/Image/ PDFs/Mercado_BR2011.pdf >. Acesso em: 29 ago. 2012.

BRASIL. Ministério do Desenvolvimento, Indústria e Comércio Exterior. Brasil maior. Brasília, 2011. Disponível em: <http://www.brasilmaior.mdic.gov.br/ publicacao/recursos/arquivos/biblioteca/Apresentacao_ PBM_-_port_rev_abril_2012.pdf > . Acesso em: 29 ago. 2012.

CHEN M. J. Competitor analysis and interfirm rivalry: toward a theoretical integration. Academy of Management Review, New York, v. 21, n. 1, p. 100134, 1996.
CHEN, M. J.; HAMBRICK, D. C. S. Stealth, and selective attack: how small firms differ from large firms in competitive behaviour. The Academy of Management Journal, New York, v. 38, n. 2, p. 453-482, april, 1995.

CLEGG, S. R.; HARDY, C. Introdução: Organização e Estudos Organizacionais. In: CLEGG, S. R.; HARDY, C.; NORD, W. R. (Org.) Handbook de estudos organizacionais. São Paulo: Atlas, 1998. (v. 1, p. 27-57)

COOPER, D. R.; SCHINDLER, P. S. Métodos de pesquisa em administração. Porto Alegre: Bookman, 2003.

COVIN, J. G.; COVIN, T. J. Competitive aggressiveness, environmental context, and small firm performance.

Entrepreneurship: Theory \& Practice, Texas, v. 14, n. 4, p. 35-50, 1990.

COVIN, J. G.; SLEVIN, D. P. Strategic management of small firms in hostile and benign environments. Strategic Management Journal, Chicago, v. 10, n. 1, p. 75-87, 1989.

COVIN, J. G.; SLEVIN, D. P. A conceptual model of entrepreneurship as firm behavior. Entrepreneurship: Theory \& Practice, Texas, v. 16, n. 1, p. 7-25, 1991.

DESS, G. G.; LUMPKIN, G. T. The role of entrepreneurial orientation in stimulating effective corporate entrepreneurship. The Academy of Management Executive, New York, v. 19, n. 1, p. 147-156, February, 2005.

FREITAS, H. et al. Elementos para guiar ações visando à orientação empreendedora em organizações de software. Revista de Administração (USP), São Paulo, v. 47, n. 2, p. 163-179, 2012.

KRÜCKEN-PEREIRA, L.; DEBIASI, F.; ABREU, A. F. Inovação tecnológica e inteligência competitiva: um processo interativo. REAd - Revista Eletrônica de Administração, Porto Alegre, v. 7, n. 3, p. 1-15, 2001. KRIPPENDORFF, K. Content analysis: an introduction to its methodology. Newbury Park, California: Sage Publications, 1980. 
LUMPKIN, G. T.; DESS, G. G. Clarifying the entrepreneurial orientation construct and linking it to performance. Academic of Management Review, New York, v. 21, n. 1, p.135-172, jan. 1996.

LUMPKIN, G. T.; DESS, G. G. Proactiveness versus competitive aggressiveness: teasing apart key dimensions of an entrepreneurial orientation. In: Frontiers of

Entrepreneurship Research, Wellesley, MA, Babson College. p. 47-58, 1997.

LUMPKIN, G. T.; DESS, G. G. Linking two dimensions of entrepreneurial orientation to firm performance: the moderating role of environment and industry life cycle. Journal of Business Venturing, v. 16, n. 5, p. 429451, sept 2001.

MACMILLAN, I. C.; DAY, D. L. Corporate ventures into industrial markets: Dynamics of aggressive entry. Journal of Business Venturing, v. 2, n. 1, p. 29-39, 1987.

MARTENS, C. D. P.; FREITAS, H. M. R.; ANDRES, R. Desenvolvimento da Orientação Empreendedora em empresas de Software: Proposições Preliminares. REAd.

Revista Eletrônica de Administração (Porto Alegre), v. 7, n. 2, p. 424-450, 2011.

MASON, J. Qualitative researching. Thousand Oaks, California: Sage Publications, 1996.

MATTOS, P. L. C. L. Análise de entrevistas não estruturadas: da formalização à pragmática da linguagem. In: GODOI, C. K; BANDEIRA-DE-MELLO, R.; SILVA,

A. B. (Org.) Pesquisa Qualitativa em Estudos

Organizacionais: Paradigmas, Estratégias e Métodos. São Paulo: Saraiva, 2006, p.347-374.

MILLER, D. The correlates of entrepreneurship in three types of firms. Management Science, v. 29, n. 7, p. 770-791, July 1983.

MILLER, D.; FRIESEN, P. H. Innovation in conservative and entrepreneurial firms: two models of strategic momentum. Strategic Management Journal, v. 3, n. 1, p. 1-26, January/March 1982.
ROSELINO, J. E.; DIEGUES, A. C. A constituição de redes produtivas globais e a Internacionalização da indústria de software. In: Encontro da ANPAD (EnANPAD), 30, 2006, Salvador. Anais... Salvador: ANPAD, 2006.

ROSELINO, J. E. Software - Relatório Preliminar Setorial. FINEP - Rede DPP, 2007. Disponível em: < http:// www.finep.gov.br/PortalDPP/relatorio_setorial/impressao_ relatorio. asp?lst_setor $=17>$. Acesso em: 20 jan. 2008.

SANDBERG, B. Creating the market for disruptive innovation: market proactiveness at the launch stage.

Journal of Targeting, Measurement and Analysis for Marketing, v. 11, n. 2, p. 184-196, sept. 2002.

SELLTIZ, C.; JAHODA, M.; DEUTSCH, M.; COOK, S. Métodos de pesquisa nas relações sociais. São Paulo: Herder, 1967.

SILVA, M. A. O. M.; GOMES, L. F. A. M.; CORREIA, M. F. Cultura e Orientação Empreendedora: uma Pesquisa Comparativa entre Empreendedores em Incubadoras no Brasil e em Portugal. Revista de Administração

Contemporânea. v. 13, n. 1, art. 4, p. 57-71, Jan./Mar. 2009.

STAMBAUGH, J. S.; YU, A.; DUBINSKY, A. J. Before the Attack: A Typology of Strategies for Competitive Aggressiveness. Journal of Management Policy and Practice, v. 12, n. 1, p. 49-63, 2011.

STAMBAUGH, J.; LUMPKIN, G. T.; BRIGHAM, K.; COGLISER, C. What makes some firms more competitively aggressive than others? Evidence from the banking industry. In: Academy of Management Proceedings, p. 1-6, 2009.

VENKATRAMAN, N. Strategic orientation of business enterprises: the construct, dimensionality and measurement. Management Science, v. 35, n. 8, p. 942-962, aug. 1989.

VORA, D.; VORA, J.; POLLEY, D. Applying entrepreneurial orientation to a medium sized firm.

International Journal of Entrepreneurial Behaviour \& Research, v. 18, n. 3, p. 352-379, 2012. 